\title{
Reassessment of Graham Steell murmur using platinum electrode technique
}

\author{
J. D. McArthur, ${ }^{1}$ I. P. Sukumar, S. C. Munsi, ${ }^{2}$ S. Krishnaswami, and G. Cherian \\ From the Department of Cardiology, Christian Medical College Hospital, Vellore 632004, S. India
}

\begin{abstract}
The Graham Steell murmur of relative pulmonary regurgitation has been reassessed using a direct technique involving injection of ascorbic acid into the pulmonary artery by needle puncture and sensing with a platinum electrode in the right ventricle. When this technique was used in 5 cases of suspected Graham Steell murmur, pulmonary regurgitation was found in all 5, while aortic regurgitation was demonstrated in one and was not assessed in one other. These results are discussed in relation to other reports concerning this murmur. In our experience, a highly selected group of patients, with high or very high pulmonary artery pressure and usually, considerably dilated pulmonary artery can be identified where the left sternal border murmur can be reliably predicted to emanate from the pulmonary valve and thus to represent a Graham Steell murmur.
\end{abstract}

After Graham Steell (1888) described the murmur now known by his name, the existence of the entity of pulmonary regurgitation associated with pulmonary hypertension due to acquired mitral valve disease was accepted for many years. However, within the past two decades, much evidence has accumulated to suggest that in the vast majority of cases, the early diastolic murmur audible at the left sternal border is due to aortic regurgitation (Runco and Booth, 1963) and that the Graham Steell murmur, while not non-existent, is a rare entity.

In a large series of cases of acquired rheumatic valvular disease with moderate to severe pulmonary hypertension seen at Christian Medical College Hospital, the authors became convinced that a small proportion of such cases could clearly be considered to have a Graham Steell murmur. This investigation was carried out to confirm or refute the impression that in certain carefully selected cases, pulmonary regurgitation can be reliably diagnosed as the origin of the left sternal border early diastolic murmur.

In order to gain objective evidence concerning the presence or absence of pulmonary regurgitation, a technique using injection of ascorbic acid by direct needle puncture of the pulmonary artery with detection of any incompetence by a platinum electrode placed in the right ventricle was de-

Received 4 January 1974.

1 Present address: Research Fellow, Department of Medical Cardiology, Royal Infirmary, Castle Street, Glasgow G4 oSF.

2 Present address: K.E.M. Hospital, Bombay, India. veloped. This technique is free from the defect of most other techniques for indicating pulmonary regurgitation, which usually require a catheter to be placed across the valve, thus giving rise to the possibility of false positive, catheter-induced pulmonary regurgitation.

\section{Subjects and methods}

The five patients investigated for pulmonary regurgitation formed a highly selected group. All the patients selected had evidence of severe mitral stenosis with at least moderate pulmonary hypertension (see Table $\mathbf{r}$ ). There was clinical evidence of pulmonary hypertension in the form of right ventricular 'heave' and loud pulmonary component of the second sound. Several patients had evidence of tricuspid valve regurgitation. All patients had an early diastolic murmur (at least grade 2/6) at the pulmonary area and left sternal border, not audible at the aortic area, and not associated with any peripheral signs of aortic regurgitation. Evidence of left ventricular enlargement on the electrocardiogram or $x$-ray or aortic root dilatation on the $x$-ray excluded the patient from the series. The patients had electrocardiographic evidence of right ventricular hypertrophy and at least moderate (sometimes gross) dilatation of the pulmonary artery on $x$-ray. All were reviewed by all the authors and were not submitted to investigation unless all the authors felt that there was a strong probability of pulmonary regurgitation being present.

One patient who had had a previous pericardectomy for constrictive pericarditis, during the course of which operation a small tear in the pulmonary artery had been produced and repaired and who now showed evidence of mild pulmonary regurgitation, was investigated with a 
TABLE I Diagnosis and findings in the five patients

\begin{tabular}{llcccc}
\hline $\begin{array}{l}\text { Case } \\
\text { No. }\end{array}$ & Diagnosis & $\begin{array}{l}\text { Systemic BP } \\
(\mathrm{mmHg})\end{array}$ & $\begin{array}{l}\text { Pulmonary artery } \\
\text { pressure } \\
(\mathrm{mmHg})\end{array}$ & $\begin{array}{l}\text { Pulmonary } \\
\text { regurgitation }\end{array}$ & $\begin{array}{l}\text { Aortic } \\
\text { regurgitation }\end{array}$ \\
\hline I & Mitral stenosis & $95 / 70$ & $85 / 45$ & + & - \\
2 & Mitral stenosis & $105 / 70$ & $95 / 35$ & + & - \\
3 & Mitral stenosis & $95 / 70$ & $120 / 70$ & + & $?$ \\
4 & Mitral stenosis & $126 / 90$ & $75 / 40$ & + & Very mild \\
5 & $\begin{array}{l}\text { Mitral stenosis, mild mitral } \\
\text { regurgitation }\end{array}$ & $80 / 55$ & $70 / 35$ & + & \\
\hline
\end{tabular}

view to establishing the diagnosis and excluding aortic regurgitation. This case was used to validate the method.

Each patient had the procedures to be carried out explained to him by one of the authors (J. McA.), with the aid of an interpreter where necessary. The patients understood that they would not benefit directly from undergoing the test and freely consented to its performance.

The technique of suprasternal puncture of the pulmonary artery was that described by Radner (1955) and was performed in each case by one of the authors (J. McA.) who had previous experience of the method.

All cases were subjected to a standard procedure. Under sedation and local anaesthesia, right heart catheterization using a bipolar platinum electrode catheter, and left heart catheterization by the retrograde route, were carried out. After completion of routine catheterization, an aortic root cineangiogram was done in the left anterior oblique projection (single plane) to assess the state of the aortic valve. In the absence of more than very mild incompetence, the right heart catheter was placed with its tip in the right ventricular outflow but clearly below the pulmonary valve and recording typical right ventricular pressures. The distal (tip) platinum electrode was connected for recording ascorbate dilution curves in the usual way. Under local anaesthesia, suprasternal puncture of the pulmonary artery using a No. I9 or 20 needle was done. Entry to the pulmonary artery was verified by pressure recording and oxygen analysis. I $\mathrm{ml}$ (100 $\mathrm{mg}$ ) ascorbic acid was quickly flushed into the pulmonary artery through the needle and the resulting deflections of the ascorbic dilution curve trace recorded on an Electronics for Medicine photographic recorder together with an electrocardiogram, right ventricular pressure trace, and a time signal.

Almost immediate deflection of the trace was considered as evidence of the presence of pulmonary regurgitation. Several traces were recorded and in several cases, the right ventricular catheter was progressively moved away from the right ventricular outflow and the injections repeated.

\section{Results}

Tracings in the patient with iatrogenic pulmonary regurgitation were uniformly positive when the right ventricular catheter was in the right ventri- cular outflow tract. This patient had no aortic incompetence on aortic angiography.

The results obtained in the patients suspected of having pulmonary incompetence are shown in Table I, together with the systemic and pulmonary artery pressure obtained at catheterization. All 5 patients showed evidence of pulmonary incompetence as shown by immediate deflection of the ascorbate trace (Fig.). However, one patient also had very mild aortic incompetence and in another, because of a technical fault, the state of the aortic valve could not be properly assessed.

\section{Discussion}

In a highly selected group of 5 patients, pulmonary regurgitation has been shown to be the only explanation for a left parasternal early diastolic murmur in three instances and a very probable cause of the murmur in two instances. Thus it is argued that with careful selection, the Graham Steell murmur can be identified and such patients differentiated from those with aortic regurgitation as a cause of the murmur.

The authors currently admit about 350 cases of mitral valve disease a year to the wards, and the 5 cases investigated were seen in a 2-year period. Therefore, though the incidence of pulmonary hypertension is high in this country, the incidence of pulmonary regurgitation appears to be low. However, for this investigation, excess caution so as not to include patients with even a suspicion of aortic regurgitation may have resulted in the exclusion of some patients with pulmonary regurgitation or with both aortic and pulmonary regurgitation.

Other authors have suggested that Graham Steell murmurs can be reliably identified (Table 2). Angelino, Levi, and Brusca (1957) demonstrated pulmonary regurgitation using reserpine to lower the pulmonary artery pressure and abolish the murmur. Cohn and Hultgren (1966) stated that three cases investigated by them could be identified as having Graham Steell murmurs and confirmed this by the absence of aortic regurgitation at operation. 


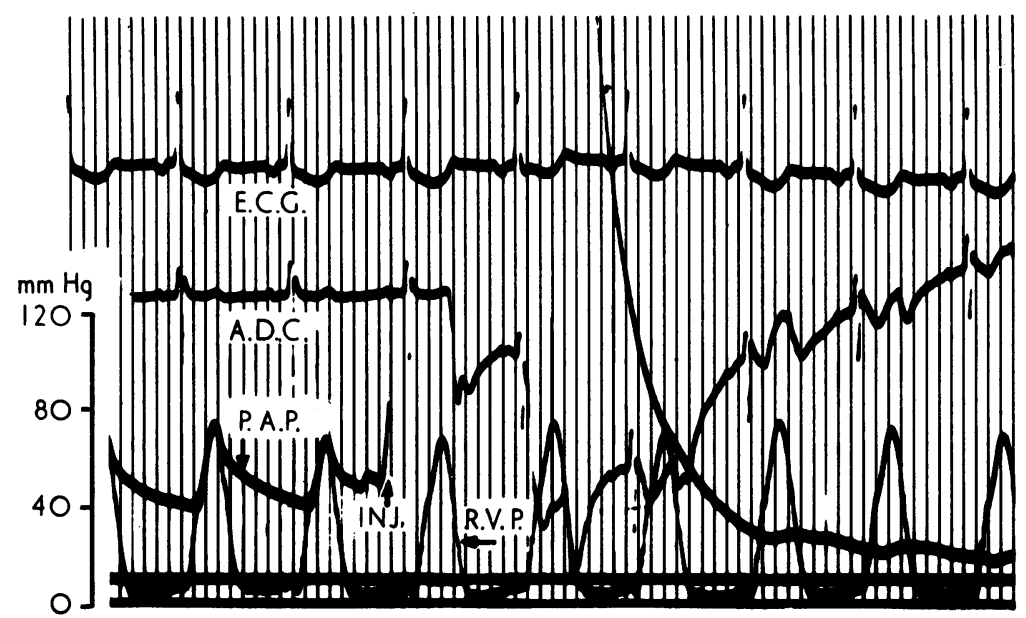

FIG. Tracing obtained in a patient showing pulmonary regurgitation. The injection (inj.) of ascorbic acid to the pulmonary artery is signalled by the sudden deflection of the trace recording pulmonary artery pressure $(P A P)$. The ascorbate dilution curve trace $(A D C)$ shows a deviation in the first diastole after injection, indicating the occurrence of pulmonary incompetence $(E C G=$ electrocardiogram; $R V P=$ right ventrcular pressure).

TABLE 2 Investigations of pulmonary regurgitation in mitral valve disease with pulmonary hypertension

\begin{tabular}{|c|c|c|c|c|c|c|}
\hline Authors & $\begin{array}{l}\text { No. of } \\
\text { cases }\end{array}$ & Technique & $\begin{array}{l}\text { Pulmonary artery } \\
\text { pressure }(\mathrm{mmHg})^{\star}\end{array}$ & $\begin{array}{l}\text { Pulmonary } \\
\text { regurgitation }\end{array}$ & \multicolumn{2}{|c|}{$\begin{array}{l}\text { Aortic } \\
\text { regurgitation }\end{array}$} \\
\hline Angelino et al. (1957) & I & $\begin{array}{l}\text { Drug (reserpine) induced } \\
\text { reduction in pulmonary } \\
\text { artery pressure }\end{array}$ & $135 / 55$ & $+\mathrm{I}$ & & $?$ \\
\hline Braunwald and Morrow (1958) & 6 & Aortography & No details & ?6 & +5 & $-I$ \\
\hline Brest et al. (1960) & 10 & $\begin{array}{l}\text { Aortography; pulmonary } \\
\text { angiography (I case) }\end{array}$ & $\begin{array}{l}27 / 18-73 / 16 \\
(3 \text { cases })\end{array}$ & - I, ?9 & & +10 \\
\hline Runco et al. (196I) & 25 & Aortography & $55 / 23-90 / 40$ & & & \\
\hline $\begin{array}{l}\text { Cohn and Hultgren (1966) } \\
\text { Runco et al. (I968) }\end{array}$ & $\begin{array}{r}3 \\
15\end{array}$ & $\begin{array}{l}\text { Observation at surgery } \\
\text { Phonocatheter and }\end{array}$ & $\begin{array}{l}\text { (3 cases) } \\
62 / 25-100 / 43\end{array}$ & $\begin{array}{r}? 25 \\
? 3\end{array}$ & +18 & $\begin{array}{l}-7 \\
-3\end{array}$ \\
\hline Weber and Burman (1968)† & 26 & $\begin{array}{l}\text { pulmonary angiography } \\
\text { Platinum electrode } \\
\text { catheter; phono- }\end{array}$ & $60 / 34-118 / 68$ & $+I,-I 4$ & ; & +15 \\
\hline Present series & 5 & $\begin{array}{l}\text { catheter } \\
\text { Platinum electrode } \\
\text { catheter with puncture }\end{array}$ & $80-100$ systolic & $+3,-23$ & & $? 26$ \\
\hline & & of pulmonary artery & $70 / 35-120 / 70$ & +5 & $+\mathrm{I},-3$ & ?I \\
\hline
\end{tabular}

$\star$ Symbols used: + No. of cases where incompetence of valve was shown to be present; - No. of cases where incompetence of valve was shown to be absent; ? No. of cases where state of valve was not assessed directly.

† Unselected series

However, as Runco et al. (1968) point out, neither technique could be considered totally reliable.

Weber and Burman (1968) (Table 2) used a technique similar to that used in this investigation except that they used a catheter passed through the pulmonary valve to inject the ascorbic acid. This leaves their technique open to the criticism that the catheter may have induced pulmonary regurgitation though, as no high pressure injection had to be made, it would be less likely to do so than when pulmonary angiography is done (when catheter 'whip' may occur). In an unselected group of patients with mitral stenosis and pulmonary hypertension, they found pulmonary regurgitation in 3 of 26 cases - a 
high incidence of 12 per cent. No clinical details concerning the murmurs audible are given, though in one case, a long diastolic murmur was recorded in the right ventricular outflow tract. If this murmur was also audible clinically, this would give an incidence of at least 4 per cent for the Graham Steell murmur.

Most investigators (Braunwald and Morrow, 1958; Brest, Udhoji, and Likoff, 1960; Runco et al., 196I, 1968) consider that the Graham Steell murmur is rare (Table 2) and cannot be reliably identified. However, while the incidence is low in this series, it is probable that all 5 cases were correctly diagnosed clinically as having a Graham Steell murmur.

In this series the pulmonary artery pressure was high or very high, in four instances approaching or exceeding systemic artery pressure. This distinguishes this series from that of Brest et al. (1960), which failed to demonstrate any pulmonary regurgitation in Io cases of suspected Graham Steell murmur (Table 2). In their series, several of the patients had only mild rises in pulmonary artery pressure. However, in by far the most satisfactory investigation of the Graham Steell murmur reported so far, that of Runco et al. (1968), though individual pulmonary artery pressures are not shown, the range of pressures reported in their series is similar to that of the present one. They found evidence of pulmonary regurgitation in only 1 of 15 cases, investigated by a special angiographic technique and intracardiac phonocardiography.

In most series previously reported (e.g. Runco et al., 196r ; Braunwald and Morrow, 1958) (Table 2), no direct evidence of the absence of pulmonary regurgitation was given but as aortic regurgitation was frequently demonstrated, it was inferred that this was the cause of the basal diastolic murmur and not pulmonary regurgitation. However, as was shown in one case of the series of Runco et al., (1968) and in one case of the present series, aortic regurgitation and pulmonary regurgitation may coexist, thus raising the possibility that pulmonary regurgitation may be more frequently present than previously inferred.

In the excellent series of Runco et al. (1968) direct evidence in the form of negative phonocatheter recordings in the right ventricle was presented to support their contention that the Graham Steell murmur is a rare entity and cannot be reliably diagnosed clinically. These results are at variance with the present series and an obvious explanation is not forthcoming. Those authors appear to have been at least as thorough in the selection of their patients and, as noted, the pulmonary artery pressures in both series are similar. We have no experience of the phonocatheter technique they used but it was shown to be reliable by them and others (Luisada, 1965). However, they warned that one had to be careful in positioning the catheter to record the intracardiac murmurs and this may suggest that their technique was less sensitive than the one used here. When one recollects the considerable sensitivity of the ascorbate dilution technique in the detection of intracardiac shunts (when the injectate has to pass round the pulmonary artery circuit before being detected and is therefore, very diluted), one can imagine that it would take only a very trivial degree of pulmonary regurgitation to give a positive result. This could well explain the high incidence of positive results found here and the results of Weber and Burman (I968) support this. Certainly, the technique would be more sensitive than the angiographic techniques also employed by the above authors and by Brest et al. (1960).

It is widely realized that rheumatic heart disease appears to run a more rapid course in India than in Western countries, with earlier appearance of significant mitral stenosis and severe pulmonary hypertension (Cherian et al., 1964; Vytilingam, Cherian, and Sukumar, 1970). Possibly these features of the disease as seen here, together with, in general, a longer delay before the patient seeks surgical treatment, are factors promoting the appearance of pulmonary incompetence in the patients investigated in this series. It is interesting to note that the only patient to have pulmonary regurgitation in the series of Runco et al. (1968) was an Indian woman!

J. D. McArthur was supported financially by the Church of Scotland.

\section{References}

Angelino, P. F. Levi, V., and Brusca, A. M. (1957). Pulmonic valvular insufficiency: a clinical and hemodynamic study. American Heart fournal 54, 182.

Braunwald, E., and Morrow, A. G. (1958). A method for the detection and estimation of aortic regurgitant flow in man. Circulation, 17, 505.

Brest, A. N., Udhoji, V., and Likoff, W. (1960). A re-evaluation of the Graham-Steell murmur. New England fournal of Medicine, 263, 1229.

Cherian, G., Vytilingam, K. I., Sukumar, I. P., and Gopinath, N. (1964). Mitral valvotomy in young patients. British Heart fournal, 26, 157.

Cohn, K. E., and Hultgren, H. N. (1966). The Graham-Stell murmur re-evaluated. New England fournal of Medicine, $274,486$.

Luisada, A. A. (1965). From Auscultation to Phonocardiography, p. 253. C. V. Mosby, St. Louis.

Radner, S. (1955). Extended suprasternal puncture technique. Acta Medica Scandinavica, 151, 223

Runco, V., and Booth, R. W. (1963). Basal diastolic murmurs. American Heart fournal, 65, 697. 
Runco, V., Levin, H. S., Vahabzadeh, H., and Booth, R. W. (1968). Basal diastolic murmurs in rheumatic heart disease: intracardiac phonocardiography and cineangiography. American Heart fournal, 75, 153.

Runco, V., Molnar, W., Meckstroth, C. V., and Ryan, J. M. (1961). The Graham Steell murmur versus aortic regurgitation in rheumatic heart disease: results of aortic valvulography. American fournal of Medicine, 31, 71.

Steell, G. (1888). The murmur of high-pressure in the pulmonary artery. Medical Chronicle, 9, 182.

Vytilingam, K. I., Cherian, G., and Sukumar, I. P. (1970). A study of juvenile mitral stenosis during a ten-year period (1958 to 1967). In Cardiology - Current Topics and
Progress, p. 187. Ed. by M. Eliakim and H. N. Neufeld. Academic Press, New York and London.

Weber, D. J., and Burman, S. O. (1968). The assessment of tricuspid and pulmonary valve disease in humans using the platinum electrode catheter technique. Fournal of Cardiovascular Surgery, 9, 237.

Requests for reprints to Dr. J. D. McArthur, Department of Medical Cardiology, Royal Infirmary, Castle Street, Glasgow G4 oSF. 